\title{
Establishing a laboratory network of influenza diagnosis in Indonesia: an experience from the avian flu $(\mathrm{H} 5 \mathrm{NI})$ outbreak
}

This article was published in the following Dove Press journal:

Clinical Epidemiology

14 August 2012

Number of times this article has been viewed

\section{Vivi Setiawaty \\ Krisna NA Pangesti \\ Ondri D Sampurno}

National Institute of Health Research and Development, Ministry of Health, the Republic of Indonesia, Jakarta, Indonesia
Correspondence: Vivi Setiawaty

Virology Laboratory, National Institute of Health Research and Development. Ministry of Health, The Republic of Indonesia, JI Percetakan Negara No 23, Jakarta 10560, Indonesia

Tel +62 2I $4288 \quad$ I754

Fax +62 2I $4288 \quad 1745$

Email vivisetiawaty@hotmail.com

\begin{abstract}
Indonesia has been part of the global influenza surveillance since the establishment of a National Influenza Center (NIC) at the National Institute of Health Research and Development (NIHRD) by the Indonesian Ministry of Health in 1975. When the outbreak of avian influenza A (H5N1) occurred, the NIC and US Naval Medical Research Unit 2 were the only diagnostic laboratories equipped for etiology confirmation. The large geographical area of the Republic of Indonesia poses a real challenge to provide prompt and accurate diagnosis nationally. This was the main reason to establish a laboratory network for H5N1 diagnosis in Indonesia. Currently, 44 laboratories have been included in the network capable of performing polymerase chain reaction testing for influenza A. Diagnostic equipment and standard procedures of biosafety and biosecurity of handling specimens have been adopted largely from World Health Organization recommendations.
\end{abstract}

Keywords: influenza, laboratory, networking

\section{Introduction}

Until recently, influenza A virus infection in Indonesia did not cause much concern for the public due to the mild, self-limiting nature of seasonal influenza. However, since the outbreaks of avian influenza A (H5N1) in poultry in 2003 and the subsequent fatal human infections in 2005, the risk of influenza caused alarm worldwide. Until the beginning of 2012, Indonesia has 189 human H5N1 cases with a mortality rate at more than $80 \%$. Therefore, there is a growing concern that H5N1 became the "new" pandemic. ${ }^{1,2}$ The big influenza pandemics that caused huge death tolls in 1918, 1957, 1968 high morbidity in 2009 are still fresh in memory. ${ }^{3}$

Laboratory assessment of influenza virus infection is an essential component for prompt and accurate diagnosis. However, this task remains difficult to accomplish in Indonesia, the largest archipelago in the world with a population of more than 235 million people. There was a strong need to establish a reliable laboratory network throughout the country to provide prompt and accurate diagnosis of influenza in suspected sufferers. Here, we review our efforts and learnings in establishing a reliable laboratory network for influenza A diagnosis during the avian flu (H5N1) outbreaks.

\section{Geographical challenges for diagnostic confirmation of avian influenza}

The Republic of Indonesia's territory extends 5120 kilometers from east to west, a similar distance as from San Francisco to New York in the United States. 
The archipelago lies from $6^{\circ}$ north latitude to $11^{\circ}$ south latitude and from $04^{\circ}$ to $141^{\circ}$ east longitude and consists of more than 17,500 islands. The inclusion of Indonesia's exclusive economic zone brings the total area to about 7.9 million square kilometers of sea area four times larger than the land area $\left(1,992,579 \mathrm{~km}^{2}\right)$. Based on the 2010 census, the total population of Indonesia is $237,556,363$ people, which are unevenly distributed among five major islands (Java, Sumatra, Kalimantan, Sulawesi, and Papua) plus the islands of Moluccas, of Bali, of West and East Nusa Tenggara, and thousands of smaller islands. Administratively, the Republic of Indonesia is divided into 33 provinces with Jakarta as the capital city. ${ }^{4}$

Laboratory confirmation is required to establish the etiology of clinical influenza and also allows the genetic characterization of viruses and identification of genetic changes favorable to the emergence of a pandemic strain. ${ }^{5}$ To monitor the circulation of influenza A virus in Indonesia, the Indonesian Ministry of Health $(\mathrm{MoH})$ initiated a surveillance program in 1975 when the National Institute of Health Research and Development (NIHRD) of the $\mathrm{MoH}$ became the National Influenza Center (NIC). This program was supported by wide collaboration among international parties such as USA Centers for Disease Control and Prevention (US CDC) and National Institute of Infectious Diseases (NIID), Japan which are the World Health Organization (WHO) Collaborating Center under the global influenza surveillance network coordinated by the WHO. However, it was not until 1999 that this surveillance became routine. Since then, all evaluation specimens of suspected influenza cases from the NIC and US Naval Medical Research Unit 2 (NAMRU-2) sentinels were sent to NIC and NAMRU-2 laboratories, respectively.

Since the first H5N1 human case until 2007, the NIC laboratory collaborated with NAMRU-2 laboratory to diagnose specimens from suspected $\mathrm{H} 5 \mathrm{~N} 1$ cases. US CDC (as a WHO Collaborating Center) and Hong Kong University (as H5N1 Reference Laboratory) have helped with confirmation and characterization of $\mathrm{H} 5 \mathrm{~N} 1$ viruses isolated from humans in Indonesia from 2005 to 2007.

Since human H5N1 infections started being reported in mid-2005, specimens of suspected cases from all over Indonesia that were requested to be confirmed by laboratory diagnostic test substantially increased. With Indonesia's geographical and demographic characteristics, specimen collections from suspected cases and time of delivery are of major concern. Throat and nose swab specimens sent to Jakarta needed 1 to 3 days to arrive. The limitation on a number of NIC laboratory staff who handle many specimens from all over Indonesia has also become a concern. Additional laboratories were required to provide timely and accurate diagnosis of influenza A (H5N1) cases throughout Indonesia. It was a real challenge for both central and province/district governments to build and develop an influenza laboratory in every province in Indonesia.

\section{Establishment of the influenza A (H5NI) laboratory network}

To increase timely diagnostic confirmation of influenza A (H5N1) virus infection, the $\mathrm{MoH}$ decided to establish a laboratory network to facilitate early detection of Influenza A (H5N1). ${ }^{5}$ In 2007, the Minister of Health issued a written policy which assigned 44 laboratories as the diagnostic laboratories for influenza A (H5N1) in Indonesia. These 44 laboratories came not only from the general hospitals under the $\mathrm{MoH}$ but also from medical schools among universities and other research institutions. They were located in 21 provinces from 33 provinces in Indonesia. These laboratories were organized as follows: two referral laboratories in Jakarta (NIHRD MoH/NIC and Eijkman Institute); eight regional labs in eight provinces and 34 subregional labs in 13 provinces. This laboratory network was finally established in 2007.

As a prerequisite, the two referral laboratories had all the necessary laboratory equipment and had more human resource capabilities than the other laboratories. However, insufficient equipment and reagents stocks in other laboratories were other challenges faced by the network.

In 2009 , the laboratory network policy was changed due to the increasing capabilities of each laboratory. Now the organization of the 44 laboratories is simpler since there are only two referral laboratories and 42 designated avian influenza laboratories. Although initially all specimens were sent to the NIC laboratory, diagnostic tests can now be performed in many more laboratories within the network. ${ }^{6-8}$

\section{The influenza laboratory network capacity}

The MoH collaborated with several donor agencies through WHO in Indonesia to provide diagnostic equipment for all the laboratories within the network in 2006. Equipment was provided based on the WHO recommendation for influenza virus detection, ie, real-time polymerase chain reaction (PCR) and gel-based PCR. ${ }^{8}$ The referral and regional laboratories should have both real-time and gel-based PCR equipment, while the subregional laboratories have only gel-based PCR equipment. Reagents stocks were kindly provided by WHO. 
In addition, a biosafety cabinet type IIA was provided in each laboratory.

In 2006, laboratory staff in NIHRD received further training for PCR and serology tests from more experienced staff at institutions such as the NIID Japan and the US CDC in Atlanta, Georgia, as the WHO Collaborating Center for Influenza for the region. Expert staff from NIHRD then trained staff in regional and subregional laboratories in PCR techniques based on the protocol developed by WHO. ${ }^{8}$ Since 2008, NIHRD has routinely given PCR training to all laboratories. Additional training to accommodate the use of different PCR primers was given when the novel influenza A (H1 N1) pandemic occurred in 2009.

The accuracy of a diagnostic test depends on the sample adequacy. Therefore, specimen collecting and delivery are important. In addition, all health personnel should adopt safe behavior when handling and preparing samples. Regarding this safety issue, the NIHRD also held periodic training in each laboratory on specimen collection, packaging, and delivery based on WHO guidelines. ${ }^{9}$ The training is not only provided to the laboratory staff, but also to the staff of hospitals, public health centers and the provincial/district health office.

To ensure quality control for specimens, the NIHRD regularly carries out external quality control (QC) scheme in each laboratory within the network. The NIHRD has developed specific test panels containing H1, H3, H5, H1N1 (2009), and influenza B strain, which are sent annually to all laboratories for this purpose. The NIHRD also checks the ribonucleoprotein (RNP) for influenza specimens serving as controls for the $\mathrm{QC}$ of specimen collection by the health personnel in the laboratory.

Lastly, the NIHRD made efforts to increase the biosafety and biosecurity of the influenza test by performing assessments of all laboratories. Recommendations were then given to the laboratories that performed to the laboratory standards of Biosafety Level 2 (BSL2). Biosafety and biosecurity training of the laboratory personnel is done periodically by the NIHRD biosafety and biosecurity team in order to maintain the safety and security of all laboratory personnel.

\section{The challenges of sustaining laboratory network services}

The Government of Indonesia faces many challenges to keep this influenza laboratory network sustainable. Firstly, the public ignorance of the impact of clinical influenza may cause a low demand for laboratory confirmation of disease etiology. ${ }^{7,10}$ As we mentioned earlier, influenza A, which commonly manifests as seasonal flu in Indonesia, was perceived as a mild condition which does not require laboratory diagnosis. This situation contributes to the small number of specimens sent to laboratories, which causes underutilization of diagnostic equipment and reagents. Secondly, rotation among health personnel is high so there is a decrease in skilled laboratory staff in many laboratories. In addition, the low demand for diagnostic confirmation in turn lowers the capability of the laboratory staff to perform PCR screening tests. Thirdly, the need to continuously provide reagent stocks, maintain laboratory equipment, and calibrate the laboratory network is costly and challenging for the $\mathrm{MoH} .{ }^{11,12}$

To overcome these problems and improve utilization of network capacity, the NIHRD issued a policy to start a stepwise approach to expand some laboratories to include a role as sentinel influenza surveillance laboratories. In 2008, three laboratories were converted to sentinel laboratories, ie, the Microbiology Laboratory of Hasanuddin University (Makassar, South Sulawesi), North Sumatra Islamic University (Medan, North Sumatra), and Diponegoro University (Semarang, Central Java). These three laboratories are expected to partially represent Indonesia. The results from these laboratories are considered good and in 2009, another two laboratories were added as sentinel laboratories, ie, the Microbiology Laboratory of Udayana University (Denpasar, Bali) and the University of Indonesia (Jakarta). Each laboratory routinely received specimens of influenzalike illness from neighboring areas of the sentinel surveillance laboratories (Figure 1). In this way, the NIHRD, together with the help from US CDC, is responsible for maintaining reagent stocks by providing updated primers and probes and calibration of equipment in every sentinel laboratory.

\section{Conclusion and future direction}

The laboratory is an important component of diagnosis during influenza outbreaks. The establishment of a laboratory network for influenza diagnosis in Indonesia was initially a response to accelerate influenza A (H5N1) confirmation throughout the archipelago. Maintenance of such networks was partly supported by international partners and was combined with the organization of a sentinel influenza surveillance laboratory network. Diagnosis of other emerging infectious diseases in addition to influenza could be a potential future development of these laboratory networks.

\section{Acknowledgment}

We thank the staff of Virology Laboratory Center for Biomedical and Basic Technology of Health, NIHRD, MoH 


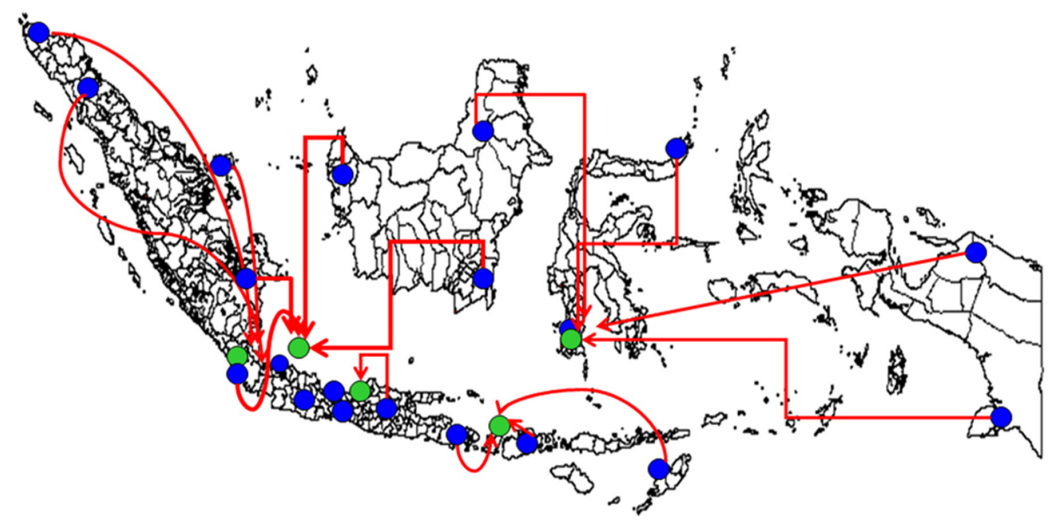

Figure I Pathways for specimen delivery to the sentinel laboratories.

Note: Blue dots represent designated avian influenza laboratories, and green dots represent the designated avian influenza and ILI sentinel laboratories.

for their contributions to provide an external quality control panel and in supervising the sentinel laboratories. We thank all the sentinel laboratory staff who supported the surveillance activity. Special thanks are due to international collaborators such as the US CDC in funding and training to support influenza surveillance in Indonesia and to the NIID in Japan for training of NIHRD laboratory staff. Additionally, we are grateful for the contributions of NAMRU-2 and Hong Kong University for their confirmation of H5N1 virus infections in humans in Indonesia in 2005-2007. We would like to thank the Eijkman Institute for their assistance in diagnostic confirmation and further characterization of H5N1 viruses while NIHRD laboratory was in development. The authors would like to thank Levina S Pakasi, Herman Kosasih, and Haditya L Mukri for their assistance in preparing the English version and laboratory map of the original manuscript.

\section{Disclosure}

The authors report no conflicts of interest in this work.

\section{References}

1. Sedyaningsih ER, Isfandari S, Setiawaty V, et al. Epidemiology of cases of H5N1 virus infection in Indonesia, July 2005-June 2006. J Infect Dis. 2007;196(4):522-527.

2. World Health Organization (WHO). Cumulative number of confirmed human cases of avian influenza A (H5N1) reported to WHO. [cited March 15, 2012]. Available from: http://www.who.int/influenza/ human_animal_interface/H5N1_cumulative_table_archives/en/index. html. Accessed March 22, 2012.

Clinical Epidemiology

\section{Publish your work in this journal}

Clinical Epidemiology is an international, peer-reviewed, open access journal focusing on disease and drug epidemiology, identification of risk factors and screening procedures to develop optimal preventative initiatives and programs. Specific topics include: diagnosis, prognosis, treatment, screening, prevention, risk factor modification, systematic

Submit your manuscript here: http://www.dovepress.com/clinical-epidemiology-journal
3. Flu.Gov. Pandemics and pandemic threats since 1900. [cited December 28, 2010]. Available from: http://www.flu.gov/pandemic/ history/index.html. Accessed February 5, 2011.

4. Central Bureau Statistics (BPS). Population census data aggregate per province in Indonesia 2010. [cited December 28, 2010]. Available from: http://www.bps.go.id/download_file/SP2010_agregat_data_perProvinsi.pdf. Accessed February 5, 2011.

5. World Health Organization (WHO). WHO accepts positive PCR test results of $\mathrm{H} 5$ infection in humans from the following laboratories, May 2011. [cited February 5, 2011]. Available from: http://www.who.int/ influenza/resources/documents/h5n1_PCR_laboratories/en/index.html. Accessed May 16, 2011.

6. Suwandono A, Sedyaningsih E, Yatim F. Development of virology and epidemiology influenza surveillance network in 2005. Media Badan Litbang Kesehatan. 2008;12(4):55-58.

7. Beckett CG, Kosasih $\mathrm{H}$, Ma'roef $\mathrm{C}$, et al. Influenza surveillance in Indonesia: 1999-2003. Clin Infect Dis. 2004;39(4):443-449.

8. World Health Organization (WHO). Recommendations and laboratory procedures for detection of avian influenza $\mathrm{A}(\mathrm{H} 5 \mathrm{~N} 1)$ virus in specimens from suspected human cases. [updated August 2007; cited February 5, 2011]. Available from: http://www.who.int/influenza/resources/documents/h5n1_laboratory_procedures/en/index.html Accessed May 16, 2011.

9. World Health Organization (WHO). Collecting, preserving and shipping specimens for the diagnosis of avian influenza A (H5N1) virus infection. Guide for field operations. [revised October 2006; cited February 5, 2011]. Available from: http://www.who.int/csr/resources/publications/surveillance/ WHO_CDS_EPR_ARO_2006_1/en/.Accessed May 16, 2011.

10. Schoub BD, McAnerney JM, Besselaar TG. Regional perspectives on influenza surveillance in Africa. Vaccine. 2002;20:S45-S46.

11. Curran MD, Ellis JS, Wreghitt TG, Zambon MC. Establishment of a UK National Influenza H5 Laboratory Network. J Med Microbiol. 2007; 56(Pt 10):1263-1267.

12. World Health Organization (WHO) Laboratory Network 2010. [cited February 5, 2011] Available from: http://www.who.int/immunization monitoring/laboratory/en/index.html. Accessed May 16, 2011.

reviews, risk \& safety of medical interventions, epidemiology \& biostatical methods, evaluation of guidelines, translational medicine, health policies \& economic evaluations. The manuscript management system is completely online and includes a very quick and fair peer-review system, which is all easy to use. 